\title{
GPS, LiDAR and VNIR data to monitor the spatial behavior of grazing sheep
}

\author{
Javier Plaza* ${ }^{a}$ | Nilda Sánchez ${ }^{a}$ (iD) | Carlos Palacios ${ }^{2}$ iD | Mario Sánchez-García ${ }^{\text {iD }}$ | \\ Jose Alfonso Abecia (iD) Marco Criado ${ }^{\text {iD }}$ | Jaime Nieto
}

aFaculty of Environmental and Agricultural Sciences. University of Salamanca, 37007 Salamanca, Spain .

Department of Cartographic and Land Engineering, University of Salamanca, 05003 Ávila, Spain.

Institute of Research in Environmental Sciences of Aragón, University of Zaragoza, 50009 Zaragoza, Spain.

*Corresponding author: pmjavier@usal.es

\begin{abstract}
Traditional knowledge about the behavior of grazing livestock is about to disappear. Shepherds well know that sheep behavior follows non-random patterns. As a novel alternative to seeking behavioral patterns, this study quantified the grazing activities of two sheep flocks of Churra breed (both in the same area but separated by 10 years) based on Global Position System (GPS) monitoring and remote monitoring sensing techniques. In the first monitoring period (2009-10), geolocations were recorded every 5 min (4,240 records), while in the second one (2018-20), records were taken every 30 min (7,636 records). The data were clustered based on the day/night and the activity (resting, moving, or grazing). An airborne LiDAR dataset was used to study the slope, aspect, and vegetation height. Four visible-infrared orthophotographs were mosaicked and classified to obtain the land use/land cover (LU/LC) map. Then, GPS locations were overlain on the terrain features, and a Chi-square test evaluated the relationships between locations and terrain features. Three spatial statistics (directional distribution, Kernel density, and Hot Spot analysis) were also calculated. Results in both monitoring periods suggested that the spatial distribution of free-grazing ewes was non-random. The flocks showed strong preferences for grazing areas with gentle north-facing slopes, where the herbaceous layer formed by pasture predominates. The geostatistical analyses of the sheep locations corroborated those preferences. Geotechnologies have emerged as a potent tool to demonstrate the influence of environmental and terrain attributes on the non-random spatial behavior of grazing sheep.
\end{abstract}

Keywords: behavioral patterns, geolocations, pastoralism, remote sensing, topographic attributes

\section{Introduction}

Historically, in the Spanish sheep industry, the control and supervision of animals have been carried out based on traditional grazing practices, which usually involve direct, continuous, or periodic observations by the shepherd (Escribano et al 2020; Bertolozzi-Caredio et al 2021). In the process, the shepherd acquires profound knowledge about the daily and seasonal behavior of the ewes concerning grazing resources and environment features, among other factors; however, the time required to acquire that knowledge, along with social (the expanding rural exodus) and economic (the detriment of extensive practices due to the higher economic profitability of intensive production systems) factors has greatly diminished traditional grazing practices and, consequently, the loss of knowledge of these animals behavior.

Given the critical situation, it is essential to introduce new technologies that contribute to developing an objective method for understanding how grazing flocks behave and which factors have the most influence. Modern extensive systems, which strive to maximize economic profitability and sustainability, might benefit from an objective analysis of the suitability of habitat for grazing as a means of improving the organization and distribution of flocks and increasing support for decision-making in sheep management (Launchbaugh and Howery 2005). Understanding the behavior of grazing flocks is a difficult challenge because the processes occur at multiple spatial and temporal scales (Senft et al 1987; Hulbert et al 2019). Nevertheless, abiotic factors (environmental, climatological, and topographical) affect the feeding behavior of ewes in free-range systems (Arnold and Dudzinski 1978; Harris et al 2002). Abiotic factors include the location of waterholes, the size, and geometry of rangelands, the topographic attributes, soils, and weather fluctuations (e.g., wind, temperature, atmospheric pressure). However, it is also important to evaluate the physiological state of the animals and the social conformation of the flock. Thus, when analyzing the distribution of grazing ewes, the environment, the flocks, and their interaction must be considered.

Technologies for monitoring flocks have proven effective and have become common among farmers. As geolocation and remote sensing technologies have become widespread, farmers have been implementing new practices 
at the expense of the more traditional ones, some of which have become almost obsolete. In the last decade, numerous Global Navigation Satellite System (GNSS) applications have been suggested as highly effective alternatives for tracking and monitoring cattle. Specifically, GPS (Global Positioning System) collars is a robust research method in science and have become a widely used technique in cattle (Ganskopp 2001; Turner et al 2001; Pandey et al 2009). In several studies, cattle location data are integrated into a Geographic Information System (GIS) in which the point cloud is overlaid on a reference map, an orthophotograph, or a Digital Elevation Model (DEM) (Turner et al 2000, 2001; Putfarken et al 2008; Schieltz et al 2017; Schoenbaum et al 2017). Other studies (Clark et al 2009; Venter et al 2019) integrated satellite images from Landsat and Sentinel-2 remote sensing missions to characterize vegetation cover. All this research demonstrated that ground-based sensors and remotely sensed satellite images could be jointly used to identify animal-landscape interactions (Handcock et al 2009). However, although these methodologies have been widely used in cattle, very little has been done in sheep.

Furthermore, scarce research has been done on the complementary use of the most advanced remote sensing technologies such as Light Detection And Ranging (LiDAR), probably because of the limited freely available data until recently. Yet, some studies (Lim et al 2003; Sillero and Gonçalves-Seco 2014), have suggested that LiDAR data are appropriate for the study of terrain and vegetation characteristics, particularly in mixed habitats such as open forests used as pasture (e.g., "dehesa", the typical Spanish agroforestry system). LiDAR uses active laser sensors to obtain a dense point cloud of the Earth's surface; specifically, it emits laser light to the ground and measures the amount of energy reflected and the time for its return. As such, it can measure the height and density of vegetation on the ground. Due to its increasing availability, in recent years, LiDAR and other remote sensing technologies; e.g., aerial photographs (Chen et al 2012; Zhang et al 2013; Su et al 2016; Shi et al 2020), thermal (Baccini et al 2012; Yandún Narváez et al 2016), and microwave imagery (Baccini et al 2012; Ghosh et al 2014) have been used extensively to map forests and vegetation characteristics.

"Dehesa" is an anthropogenic ecosystem that involves traditional forest exploitation of holm oak that creates open spaces between trees, which become over time grasslands and meadows dominated by herbaceous and shrub plant species that are consumed by livestock (Escribano 2019). As in other natural grazing habitats, the spatial-temporal heterogeneity of the vegetation has a strong influence on the behavior of grazing animals and their spatial distribution. The presence of over-or under-grazed areas caused by an uneven distribution of grazing can immediately affect the efficiency of forage resource use, which might affect the productivity and biodiversity of grasslands (Herrera 2018).

The work hypothesizes that it is possible to identify behavioral patterns of pastoralist sheep related to terrain attributes and environmental conditions using innovative remote sensing techniques. GPS monitoring and remote sensing resources may offer a great potential to quantify the behavioral patterns of grazing sheep flocks. To do so, data recorded with GPS devices, together with airborne visible and near-infrared (VNIR) imagery and LiDAR data were exploited on two grazing sheep flocks.

\section{Materials and Methods}

\subsection{Study area}

The study was carried out in 800 ha of communal

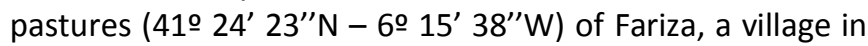
the Sayago region of the province of Zamora (Castile and Leon, Spain) (Figure 1). Fariza belongs to a natural area, part of the Natura 2000 Network; specifically, it is part of the "Arribes del Duero" Natural Reserve. The ecosystem known as the "dehesa", predominates in the study area.

The semi-arid Mediterranean climate, the diverse topography, and the poor quality of siliceous soils are the main characteristics that have led to these areas being used for extensive livestock farming. Most of the study area was within a rangeland, where other types of vegetation were present: holm oak "dehesa", pastures, shrubs (rockrose, heather, and thyme), and oaks of different heights and densities (Figure 1). In addition, some small areas were used to cultivate dry-land cereals. The area's diversity provided the sheep flocks with a wide variety of habitats for grazing.

The study area has a communal use; i.e., the land belongs to the municipality and all residents have the right to graze their livestock in the area. Apart from fences and one road (Figure 1, in black), there were no other physical barriers to impede the free movement of the animals.

\subsection{Flock monitoring}

This study involved two geolocation datasets derived from GPS collars on two sheep flocks that were collected 10 years apart. There were significant advances in geomatics in the intervening period, particularly in the geolocation devices and networks. However, it was assumed that the management system was the same for both flocks. Therefore, the second objective is to assess if the sheep's non-random grazing behavior may be detected by GPS devices, regardless of the technological level of those devices.

Both flocks were Churra breed sheep, characterized by having a medium size, a rustic metabolism, a meat/dairy aptitude, a white coat with black or peripheral brown coloring of the ear tips, around the eyes, nose, and distal parts of the limbs. Specifically, the ewes were the "sayaguesa" ecotype. Both flocks were maintained under a free grazing system.

The monitoring system consisted of a GPS sensor, a data storage unit, a GPRS SIM card, a long-life battery, and an antenna for receiving the satellite signal (most of the elements of the device were inside a hard plastic case with a hermetic seal, which protected them against shock and moisture). The first monitoring period took place between 
2009 and 2010 (hereafter, 09-10 period) and the second period between 2018 and 2020 (hereafter, 18-20 period). Although the flocks differed in size, the management operations were the same for both flocks. The specifics of each monitoring period are described below.
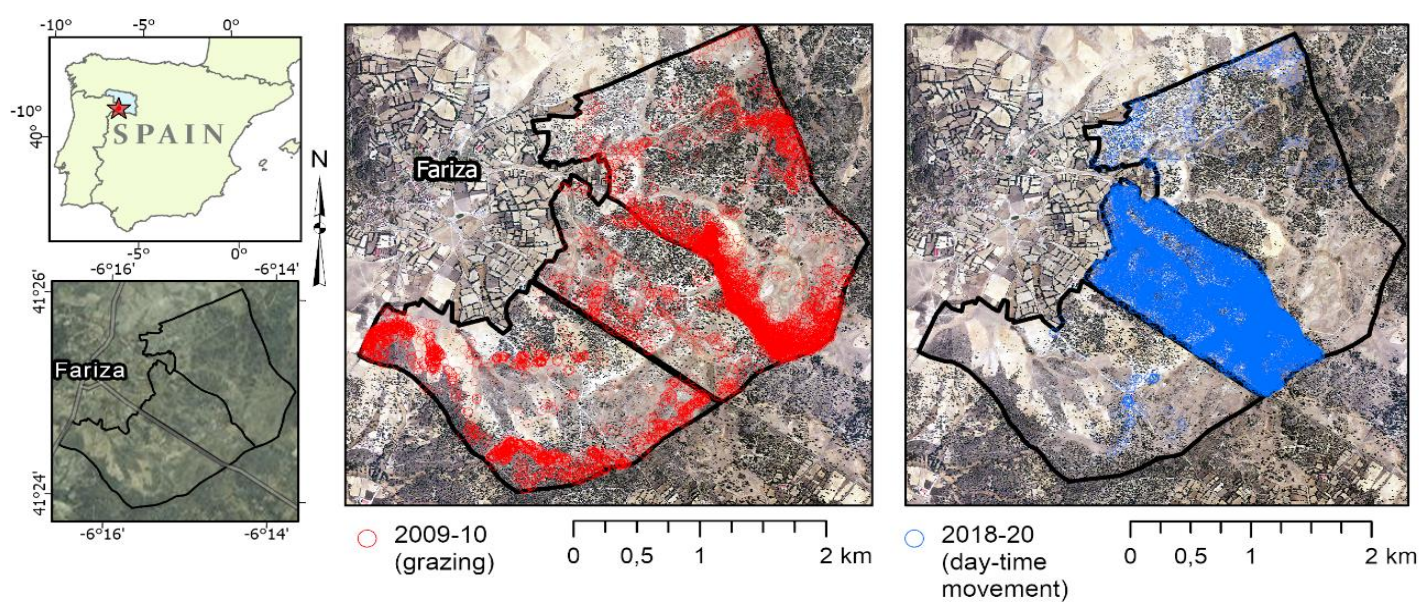

Figure 1 Location of the study area in Fariza, Spain.

\subsubsection{9-10 monitoring period}

The flock contained 614 reproductively mature animals ( 600 breeding females and 14 males), and GPS collars were placed on two healthy, randomly selected adult female ewes. Each time the battery was changed (every 15 recording days approximately), the GPS collar was placed on another two randomly selected female sheep; therefore, the data were not biased by the behavior of a single individual. A total of 12 ewes were monitored throughout this period. The GPS collars were prototypes developed by CONAN-GPS (GMV Innovating Solutions S.L., Valladolid, Spain). Geolocation data were collected every $5 \mathrm{~min}$ and daily sent to a Machine to Machine (M2M) platform via a GPRS connection.

The distance, time, and speed between consecutive GPS records were calculated at daily interval. The animal activity was defined based on the animal's speed. To do so, simultaneous to the data collection by the GPS devices, the flock's behavior was observed directly. These direct observations were taken after placement of the GPS device for each of the 12 monitored ewes. Specifically, these measurements were taken every 15 minutes along eight hours per day during the first two days of their monitoring. The observations were compared with the GPS locations and trajectories to classify the data set based on the animal's speed between two consecutive locations. Thus, the main activity of the flock was identified, distinguishing between resting, grazing or moving, specifically, speed $<0.043 \mathrm{~m} / \mathrm{s}=$ "resting", $0.043 \mathrm{~m} / \mathrm{s}$ to $0.4 \mathrm{~m} / \mathrm{s}=$ "grazing", and $>0.4 \mathrm{~m} / \mathrm{s}=$ "moving" (Sánchez-García, 2010). These activities have been defined similarly for cattle (Mora-Delgado et al 2016; Venter et al 2019), albeit the speed ranges are not the same since they are different species. Note that "grazing" is the target class of the study as it is the only one that implies the act of consuming grass.

\subsection{2. $18-20$ monitoring period}

The flock had 650 reproductively mature animals (645 breeding females and 5 males), and the GPS devices that recorded geolocations were GPS DMS-CattleSat 1.4 with a UBX-R3 receiver chip (Domodis, Cordovilla, Spain). As in the previous monitoring period, two GPS collars were placed on two healthy randomly selected adult female ewes, which were moved from one individual to another each time the battery had to be replaced (every 90 recording days approximately). A total of 18 ewes were monitored throughout this period. Data transmission was similar to that in 09-10 and was web-accessible. The number of data was higher than in 09-10 because of the time series was continuous, even though the data recording interval was longer (every $30 \mathrm{~min}$ ). Then, the same speed clustering as done in 09-10 was not possible.

Nevertheless, the speed between two consecutive locations was used to create a dichotomous analysis of the animal's movement, i.e., "rest" (if speed =0) and "movement" (if speed $>0$ ). In addition, based on sunrise and sunset times in each month, data were categorized as "daytime" or "night-time". This distinction can provide important information about the timing of active grazing by the animals, their spatial distribution in the study area, and the location of the sheepfolds used by the farmers to shelter the sheep at night. In short, the data were assigned to four groups: (1) daytime movement, (2) night-time movement, (3) day-time rest, and (4) night-time rest. Of those, the only day-time movement was associated with grazing.

\subsection{Airborne data}

\subsubsection{LiDAR data}

LiDAR data provides several vegetation and terrain observations at a fine spatial scale. The airborne LiDAR dataset was provided by the Agriculture Technological Institute of Castile and León in 2010 (ITACYL), available at http://ftp.itacyl.es/cartografia/02_Altimetria/023_LIDAR. 
The point cloud (Figure 2a) had a point density of one point per $2 \mathrm{~m}^{2}$ and an accuracy of $15-20 \mathrm{~cm}$ for $Z$ and $10-15 \mathrm{~cm}$ for $X Y$. Before extracting any derived product, a workflow of refinement and editing was performed on the .las files, including removing overlapped and outlier points, deleting duplicates, identifying noisy points, and reclassifying. This was performed in ArcGIS Pro 2.4 and the LAStools LiDAR processing toolbox (https://rapidlasso.com).

After refinement, the LiDAR point cloud (Figure 2a) was rasterized into the Digital Terrain Model (DTM) (Figure $2 b$, top) and the Digital Surface Model (DSM) (Figure 2b, bottom). To match the original point density, the spatial resolution of the two raster files was set to $2 \mathrm{~m}$. In both cases, elevation was interpolated; however, for the DTM, the points classified as ground data were selected, whereas, for the DSM, a filter of the first return signal was applied. It was shown that using the first return of the signal may lead to an underestimation of the crown height because the probability that a small footprint laser pulse intercepts the apex of a conic crown is low (Lim et al 2003). In the study area, however, the trees (mostly Quercus ilex) have a rounded, typically plain crown, which is not affected by this problem.

Based on the DTM, several terrain features were evaluated, including watershed slope, aspect, flow direction, and accumulation. A preliminary assessment identified slope and aspect as key attributes. In addition, the Canopy Height Model (CHM) was calculated by subtracting the DTM from the DSM. Therefore, the elevation, slope, CHM, and aspect of the whole study area were extracted and analyzed at each location of the monitored sheep.

\subsubsection{Aerial photographs and classification map}

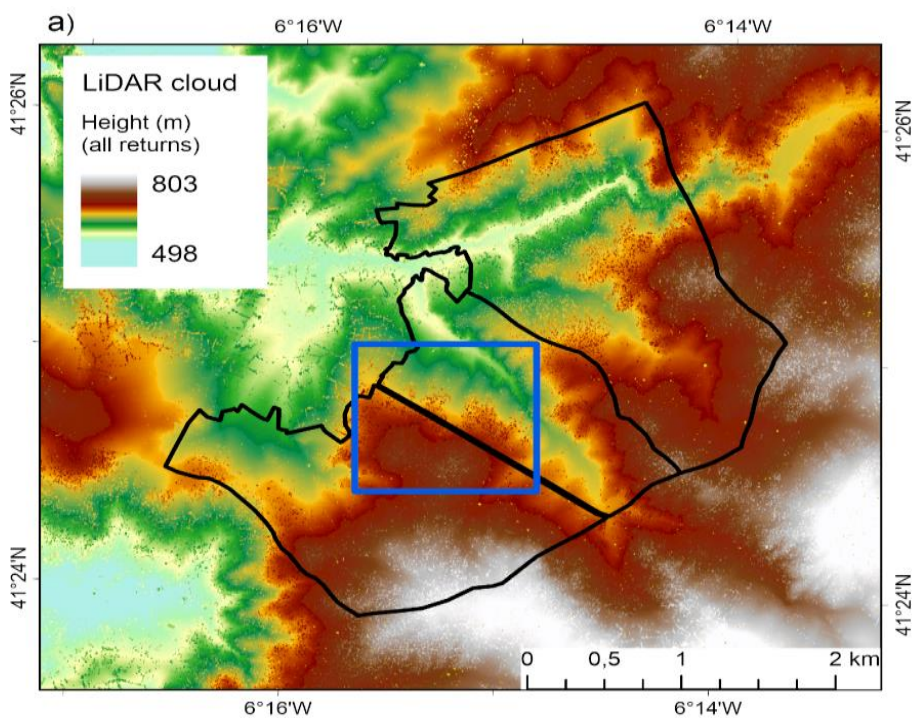

Figure 2 (a) LiDAR data with a point cloud density representation and the locations of the study area, and (b) details of the rasters DTM (top) and DSM (bottom) of the study area.

\subsection{Analysis of spatial distribution by spatial statistics}

Several spatial statistics were suggested as an objective way to identify both the empirical relationships
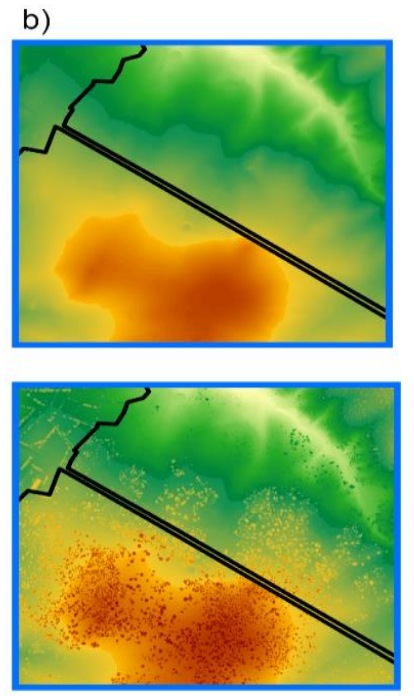

Four orthophotos from the ITACYL at $25-\mathrm{cm}$ spatial resolution were mosaicked to cover the study area, including three RGB bands and one NIR.

To investigate the LU/LC in the study area, a supervised classification was tested by the ArcGIS Pro 2.4 schema of pixel-based classification and the Support Vector Machine algorithm (Priya et al 2012; Saini and Ghosh 2018). The training dataset consisted in 100 ground-truth points randomly selected in the orthophotos, in which their LU/LC was estimated from the VNIR images. To reinforce the classification, the Normalized Difference Vegetation Index (NDVI) between red and NIR bands was calculated and used as a reference map in the process. The proposed legend identified the most common grazing scenarios, i.e., trees and/or shrublands, rainfed crop areas, grasslands and pasture, roads and tracks, and rocky-asphalt patches. The accuracy of the map produced was evaluated by a confusion matrix, a tool that allows a comparison of the real class and the class that resulted from the process within a range of known areas. Each column of the matrix indicates the number of predictions of each class, and each row indicates the instances in the real class. The tool calculates errors of omission and commission, the index of agreement (or kappa concordance), and an overall precision between the classified map and the reference data. For that purpose, a dataset of other 100 ground-truth points, previously selected in the orthophotos, was used as reference. Then, statistics were extracted from the expected vs. observed values, a typical schema of the accuracy assessment used in classifications (Foody 2002; Lillesand et al 2015). Similarly to the other LiDAR-derived maps, each GPS position was overlaid on the resulting LU/LC map, and each class was extracted for each record.

between factors that influence grazing and the spatial patterns of the flock based on the GPS locations. Only the temporal continuity of the 18-20 data allowed that analysis. 
A first analysis evaluated the directional distribution of the GPS point cloud. Standard deviation ellipses were used to quantify the spatial characteristics of the geographical features such as central tendency, dispersion, and directional trends.

Given the large number of records available, it is likely that locations might have been concentrated in some areas. Specifically, we evaluated the clustering patterns based on their statistical significance: from "hot" to "cold" spots (HS and CS, respectively). In addition, the Kernel Density Spatial Interpolation provided indications of the possible locations of the HS. The ArcGIS Pro spatial statistics tool calculates a magnitude per unit area from the points of the geolocations based on a kernel function (Silverman 1986), which includes the point density around each raster output cell.

\subsection{Statistical analysis}

The influence of several biotic and abiotic factors was studied over the two databases, i.e., aspect, slope, CHM (canopy height model), and LU/LC map. Histograms and statistics (observed and expected frequencies together with the Chi-square analysis) indicated the conditions preferred by sheep for grazing. Unfortunately, neither LIDAR data nor infrared orthophotos of the study area were available for 2018-2020. Therefore, the LU/LC map and the CHM could not be created for this period. Nevertheless, the topographical factors of the terrain (slope and aspect) are not supposed to differ between the two periods; therefore, the same maps were used for both periods.

To discard any correlations between the topographic features extracted from the LIDAR dataset, the spatial correlation (Pearson's Linear Correlation Coefficient, R) between the slope maps, the aspect, and the CHM were calculated. The correlations between slope and aspect (0.02), aspect and CHM (-0.02), and CHM and slope (-0.04) were not statistically significant. Thus, they may be considered independent features.

All variables of interest (aspect, slope, $\mathrm{CHM}$, and LU/LC) were expressed as codified values; therefore, the Chisquare test was used to evaluate the independence between two categorical variables. Here, the objective was to obtain an absolute value of dependence between the terrain variables or expected frequencies $\left(\mathrm{N}_{\mathrm{E}}\right)$ and the sheep locations or observed frequencies $\left(\mathrm{N}_{0}\right)$ with no influence by the terrain itself; e.g., if a certain slope predominates the terrain, it is likely that that slope will occur more frequently among the sheep locations. To avoid that problem, the $N_{E}$ in the Chi-square tests were not equally distributed; indeed, they were adjusted to the percentage occupied by each class variable. Therefore, the $\mathrm{N}_{\mathrm{E}}$ were different and duly adjusted to the terrain distribution of the variables.

\section{Results}

\subsection{9-10 monitoring period}

The records were collected over 87 days: 63 days from February to December 2009 (scattered days of February, April, July, October, and December) and 24 days from January 2010. GPS devices recorded 12,652 locations, out of which 5,391 (42.61\%) positions corresponded to resting activity, $3,021(33.51 \%)$ to moving and 4,240 (23.88\%) to grazing.

\subsubsection{Effect of vegetation height}

To classify the various vegetation strata in the study area, the classification of the Food and Agriculture Organization of the United Nations (FAO 2004) was followed. Accordingly, the herbaceous layer was considered the vegetation cover that did not exceed $0.5 \mathrm{~m}$ in height, the shrub layer was the vegetation between 0.5 and $3 \mathrm{~m}$, and the tree layer was the vegetation cover that was $>3 \mathrm{~m}$ high (Figure 3).

In the CHM map, the area occupied by each class $\left(\mathrm{N}_{\mathrm{E}}\right)$ was $81.2 \%$ herbaceous, $10.0 \%$ trees, and $8.8 \%$ shrub (Table 1). Sheep locations at the CHM map indicated that ewes tended to graze in areas that were distant to the highest vegetation strata. The $\mathrm{N}_{O}$ indicated that grazing occurred mainly on the herbaceous layer (71.6\% of locations). Only $18.2 \%$ of the locations occurred under trees, and $10.2 \%$ occurred on scrublands. The remnants revealed that there were clear differences between $\mathrm{N}_{\mathrm{E}}$ and $\mathrm{N}_{\mathrm{O}}$, and their statistical significance was confirmed $(P<0.05)$ by the ChiSquare test value $\left(\chi^{2}\right)$.

Table 1 Expected and observed frequencies in CHM (09-10 monitoring period).

\begin{tabular}{cccccc}
\hline Variable & & $\mathrm{N}_{\mathrm{O}}$ & $\mathrm{N}_{\mathrm{E}}$ & $\mathrm{R}$ & $\chi^{2}$ \\
\hline \multirow{2}{*}{$\mathrm{CHM}$} & Herbaceous layer & $3,036(71.6 \%)$ & $3,444(81.2 \%)$ & $-408(-9.6 \%)$ & \\
& Shrub layer & $434(10.2 \%)$ & $374(8.8 \%)$ & $+60(+1.4 \%)$ & 344.936 \\
& Tree layer & $770(18.2 \%)$ & $422(10.0 \%)$ & $+348(+8.2 \%)$ & \\
\hline
\end{tabular}

* Statistically significant differences $P<0.05$

${ }^{*} \mathrm{~N}_{\mathrm{O}}$ : Observed frequencies (sheep locations distribution); $\mathrm{N}_{\mathrm{E}}$ : Expected frequencies (terrain distribution); $\mathrm{R}:$ Remainder; $\chi^{2}:$ Chi-square value

\subsubsection{Effect of aspect}

The aspect map (Figure 4) depicts the four main compass directions taken into account. Northern areas range from $292.5^{\circ}$ to $67.5^{\circ}$, eastern areas from $67.5^{\circ}$ to $112.5^{\circ}$, southern areas from $112.0^{\circ}$ to $202.5^{\circ}$, and western areas from $202.5^{\circ}$ to $292.5^{\circ}$, whose $\mathrm{N}_{\mathrm{E}}$ are shown in Table 2 . The distribution of locations differed significantly $(P<0.05)$ 
among aspects. Remarkably, $64.6 \%$ of the observations $\left(\mathrm{N}_{0}\right)$ are located on north-facing areas, followed by west-facing areas with $19.6 \%$, then south-facing areas with $8.6 \%$, and finally east-facing areas with $7.2 \%$ (Table 2 ).

\subsubsection{Effect of slope}

Except for some isolated escarpments and small gullies along the main river, the slope of the study area was very gentle (Figure 5). Specifically, most of the slopes spanned between $2 \%-6 \%$ (Table 3). Most $(77.5 \%)$ of the sheep locations were on slopes that were $<6 \%$.

The ewes' geolocations (NO) slopes had a normal distribution, with an average of $4.76 \%$, and quartiles $\mathrm{Q}_{1}=2.57 \%, \mathrm{Q}_{2}=3.79 \%$, and $\mathrm{Q}_{3}=5.69 \%$. The highest number of records was in the range $2-4 \%$, followed by the range $4-6 \%$ and the range $>6 \%$. Ewes preferred gentle slopes for grazing (particularly between $2 \%$ and $4 \%$ ), although they were not the most common slope in the study area (Table 3).

Table 2 Expected and observed frequencies of aspect (09-10 monitoring period).

\begin{tabular}{|c|c|c|c|c|c|c|}
\hline Variable & & $\mathrm{N}_{\mathrm{O}}$ & $\mathrm{N}_{\mathrm{E}}$ & $\mathrm{R}$ & $\chi^{2}$ & $P$-value \\
\hline \multirow{4}{*}{ Aspect } & North & $2,738(64.6 \%)$ & $1,548(36.5 \%)$ & $+1,190(+28.1 \%)$ & \multirow{4}{*}{1466.822} & \multirow{4}{*}{0.000} \\
\hline & East & $304(7.2 \%)$ & 726 (17.1\%) & $-422(-9.9 \%)$ & & \\
\hline & South & 365 (8.6\%) & 689 (16.2\%) & $-324(-7.6 \%)$ & & \\
\hline & West & 833 (19.6\%) & $1,277(30.2 \%)$ & $-444(-20.6 \%)$ & & \\
\hline
\end{tabular}

*Statistically significant differences $P<0.05$

${ }^{*} \mathrm{~N}_{\mathrm{O}}$ : Observed frequencies (sheep locations distribution); $\mathrm{N}_{\mathrm{E}}$ : Expected frequencies (terrain distribution); R: Remainder; $\chi^{2}:$ Chi-square value

Table 3 Expected and observed frequencies of slope (09-10 monitoring period).

\begin{tabular}{cccccc}
\hline Variable & & $N_{\mathrm{O}}$ & $\mathrm{N}_{\mathrm{E}}$ & $\mathrm{R}$ & $\chi^{2}$ \\
\hline & $0-2$ & $580(13.7 \%)$ & $364(8.6 \%)$ & $+216(+5.1 \%)$ & \\
Slope & $2-4$ & $1,688(39.8 \%)$ & $1,229(29.0 \%)$ & $+459(+10.8 \%)$ & 498.515 \\
& $4-6$ & $1,019(24.0 \%)$ & $1,190(28.1 \%)$ & $-171(-4.1 \%)$ & 0.000 \\
& $>6$ & $953(22.5 \%)$ & $1,457(34.3 \%)$ & $-504(-11.8 \%)$ & \\
\hline
\end{tabular}

*Statistically significant differences $P<0.05$

${ }^{*} \mathrm{~N}_{\mathrm{O}}$ : Observed frequencies (sheep locations distribution); $\mathrm{N}_{\mathrm{E}}$ : Expected frequencies (terrain distribution); R: Remainder; $\chi^{2}$ : Chi-square value

\subsubsection{Effect of $L U / L C$}

The LU/LC map (Figure 6) had a kappa concordance index of 0.76 and an average accuracy of $84 \%$. Given that a kappa index of 1 indicates the closest concordance and that the minimum level of interpretation accuracy in the identification of LU/LC categories based on a remote sensor should be at least $85 \%$ (Anderson et al 1976), the results of the LU/LC map were considered acceptable.

Grasslands, followed by trees and shrub layers, were the most common LU/LC (Table 4). Grazing sheep made the most use of grasslands and tree and shrub strata to a lesser extent (Table 4).

\subsection{8-20 monitoring period}

The locations of ewes in the 18-20 flock were recorded from 1 Jan 2018 to 14 Apr 2020 ( $N=18,044$ records). Of those records, $42.3 \%$ indicated day-time movement, $14.6 \%$ indicated night-time movement, $9.9 \%$ indicated day-time rest, and $33.2 \%$ indicated night-time rest.

Although the number records differed between flocks in each period, the frequencies of slope and aspect of the terrain $\left(\mathrm{N}_{\mathrm{E}}\right)$ were the same because the terrain's topography remained unaltered.

\subsubsection{Effect of aspect}

As in the 09-10 flock, ewes in 18-20 showed a significant $(P<0.05)$ preference for north-facing areas (Table 5).

\subsubsection{Effect of slope}

Similar to the $09-10$ period, $64.9 \%$ of the locations occurred in areas with a slope $<6 \%$. This value is slightly smaller than its counterpart from the other monitoring period but confirms that the sheep show a preference for gentle slopes. The slopes of the geolocations had a normal distribution, an average of $5.6 \%$, and quartiles $\mathrm{Q}_{1}=3.26 \%$, $\mathrm{Q}_{2}=4.89 \%$, and $\mathrm{Q}_{3}=6.97 \%$ (Table 6).

\subsubsection{Analysis of spatial distribution}

For the 18-20 flock, the standard deviation ellipse (Figure 7, left) encompassed about $68 \%$ of the geolocations. It indicated a faster change in the southwest-northeast 
direction and a more gradual change in the northwestsoutheast direction.

The Kernel Density analysis indicated HS presence in the study area (Figure 7, center). In particular, a very high point density occurred at the southeast end of the center of the communal pastures. Of the 7,636 geolocations, $43.0 \%$ were located in HS. To study the causes of the formation of

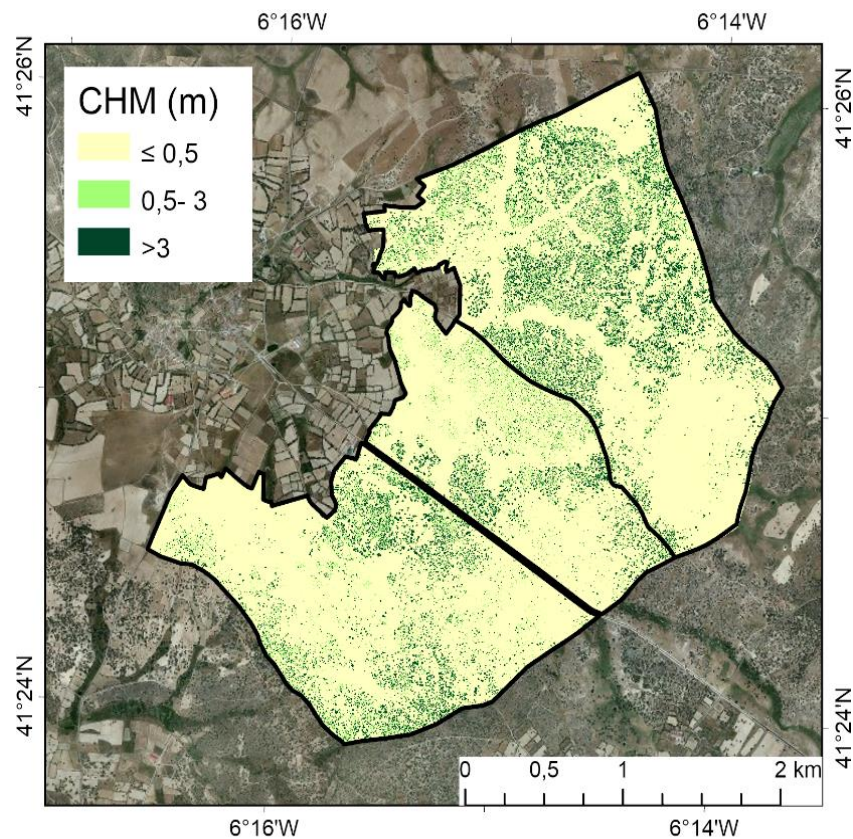

Figure 3 Map of CHM derived from the subtraction of the DSM from the DTM of the study.

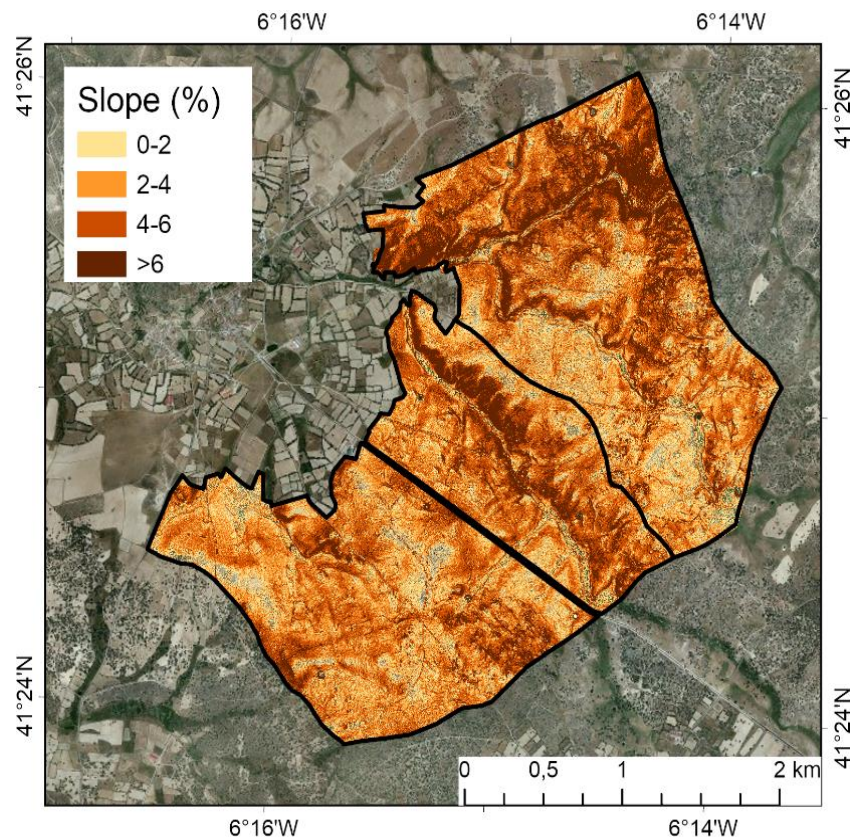

Figure 5 Map of slope within the study area.

\section{Discussion}

\subsection{Selection of the dominant factors influencing grazing}

this HS, that area was isolated (Figure 7, right), and the slope and aspect factors were studied within it. Within the HS, the most common slope was $>6 \%$ (Table 7). Among the geolocations ( $n=3,285)$ in the HS, however, the highest proportion has slopes of $2-4 \%$ (Table 7). In the $\mathrm{HS}\left(\mathrm{N}_{\mathrm{E}}\right.$ in Table $7)$, west-facing areas were the most common (49\%); however, the ewes preferred north-facing areas (55.8\%).

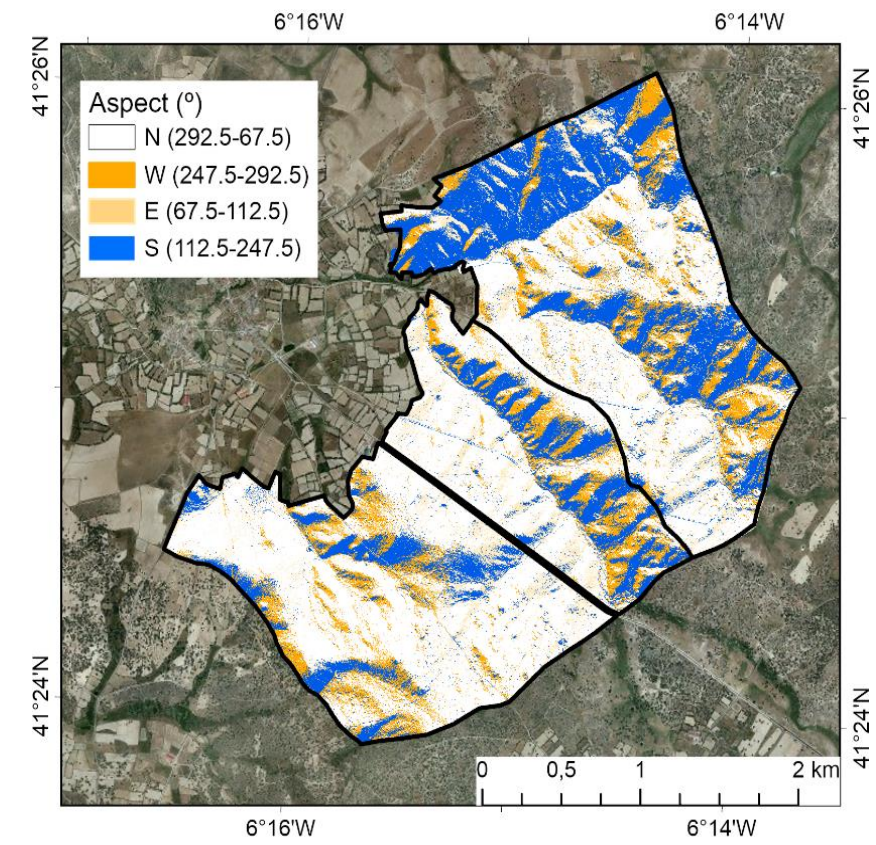

Figure 4 Map of aspect within the study area.

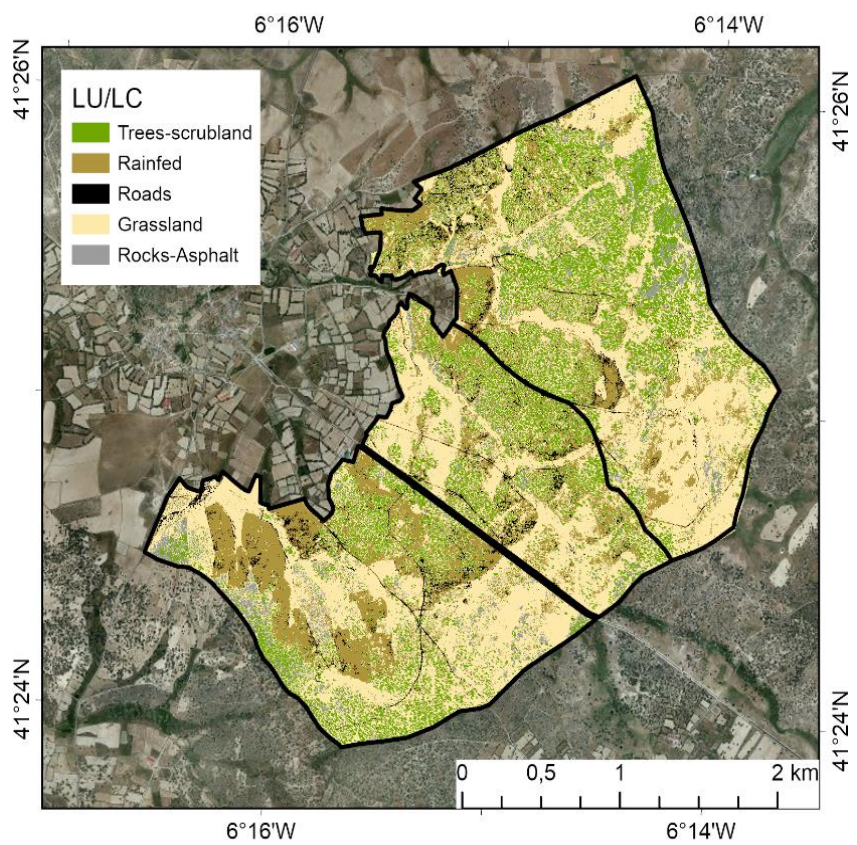

Figure $6 \mathrm{Map}$ of LU/LC within the study area.

Biotic and abiotic factors affect the spatial and temporal patterns of livestock behavior and land use (Schoenbaum et al 2017). The geodata afforded several mapping products, which described the main factors that 
appeared to be drivers of the grazing locations in this study, i.e., aspect and slope, $\mathrm{CHM}$ (vegetation height), and the LU/LC map. Therefore, other factors did not show a clear pattern and were discarded. For example, a preliminary analysis of the grazing locations indicated no clear relationship with water bodies (mainly small creeks and pools). Direct observations in the 09-10 monitoring period indicated that, in general, ewes did not exhibit an active search for water sources. Therefore, the "water" factor was excluded. In addition, no artificial boundaries (except the main road) existed in the study area; thus, there were no limits to the flock movement.

\subsection{Effect of vegetation height}

Sheep always graze close to ground level, and studies have found an inverse relationship between sheep grazing preferences and vegetation cover height (Schieltz et al 2017). Even though the trees and shrubs in the "dehesa" provide shelter from the heat and other adverse weather conditions, ewes demonstrated a preference for other areas to feed. Glimp and Swanson (1994) demonstrated that sheep are reluctant to go into areas with dense vegetation and vegetation higher than their line of sight. Furthermore, studies have shown that pastures that grow under mature tree canopies have a lower nutritional value (Percival and Knowles 1983).

\subsection{Effect of $L U / L C$}

The strong predilection of sheep for grasslands, which are areas where the herbaceous layer predominates, supports the results from the CHM model, which indicated the preference of the ewes for pastures and grasslands for grazing. However, those preferences might be contradicted by the long-held common belief that sheep eat all types of vegetation (and on any slope) if food is in short supply. At those times, their diet can consist of $80 \%$ leaves from shrubs and woody vegetation above one $m$ in height (Fernández Carmona et al 2017). Our study has shown that if sheep choose where to graze, they will always choose grasslands and pastures and the shrub layer to a lesser extent. In a study of the feeding habits of sheep and goats in Portugal (Castro and Fernández-Núñez 2016), goats had significantly more tree and shrub species than sheep, and the sheep diet was $84 \%$ herbaceous plant species.
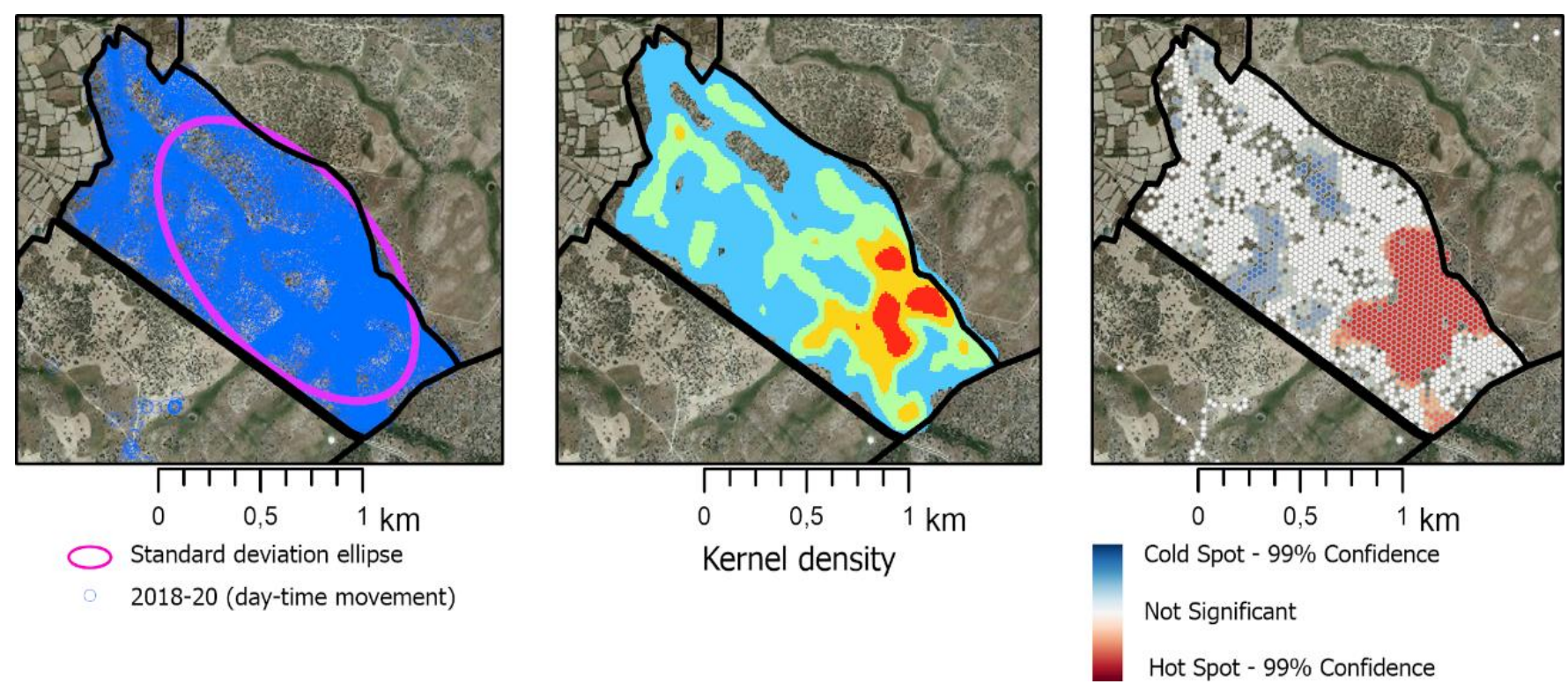

Figure 7 Standard deviation ellipse (left), kernel density (center), and hot spots (right) for the geolocation of sheep in the 2018-20 monitoring period.

Table 4 Expected and observed frequencies of LU/LC (09-10 monitoring period).

\begin{tabular}{|c|c|c|c|c|c|c|}
\hline Variable & & $\mathrm{N}_{\mathrm{O}}$ & $\mathrm{N}_{\mathrm{E}}$ & $\mathrm{R}$ & $\chi^{2}$ & $P$-value \\
\hline \multirow{5}{*}{ LU/LC } & Trees and/or shrub layer & $1,124(26.5 \%)$ & $864(20.4 \%)$ & $+260(+6.1 \%)$ & \multirow{5}{*}{160.700} & \multirow{5}{*}{0.000} \\
\hline & Rainfed land & $566(13.4 \%)$ & $806(19.0 \%)$ & $-240(-5.6 \%)$ & & \\
\hline & Roads and tracks & 125 (2.9\%) & $133(3.1 \%)$ & $-8(-0.2 \%)$ & & \\
\hline & Grasslands & $2,178(51.4 \%)$ & $2,136(50.4 \%)$ & $+42(+1.0 \%)$ & & \\
\hline & Rocks and asphalt & 247 (5.8\%) & 301 (7.1\%) & $-54(-1.3 \%)$ & & \\
\hline
\end{tabular}

*Statistically significant differences $P<0.05$

${ }^{*} \mathrm{~N}_{\mathrm{O}}$ : Observed frequencies (sheep locations distribution); $\mathrm{N}_{\mathrm{E}}$ : Expected frequencies (terrain distribution); R: Remainder; $\chi^{2}$ : Chi-square value 
Table 5 Expected and observed frequencies of aspect (18-20 monitoring period).

\begin{tabular}{rcccc}
\hline Variable & & $\mathrm{N}_{\mathrm{O}}$ & $\mathrm{N}$ & $\mathrm{R}$ \\
\hline & North & $4,274(56.0 \%)$ & $2,788(36.5 \%)$ & $+1,486(+19.5 \%)$ \\
Aspect & East & $320(4.2 \%)$ & $1,307(17.1 \%)$ & $-987(-12.9 \%)$ \\
& South & $718(9.4 \%)$ & $1,240(16.2 \%)$ & $-522(-6.8 \%)$ \\
& West & $2,324(30.4 \%)$ & $2,301(30.2 \%)$ & $+23(+0.2 \%)$ \\
\hline
\end{tabular}

*Statistically significant differences $P<0.05$

${ }^{*} \mathrm{~N}_{\mathrm{O}}$ : Observed frequencies (sheep locations distribution); $\mathrm{N}_{\mathrm{E}}$ : Expected frequencies (terrain distribution); R: Remainder; $\chi^{2}$ : Chi-square value

\subsection{Effect of aspect}

Probably, the apparent preference for north-facing lands is because, at the latitude of the study area, the conditions in these particular areas are the best for the growth of pastures with the best nutritional characteristics and highest density. Some authors (Nadal-Romero et al 2014) have suggested that south-facing slopes tend to have less vegetation than do north-facing slopes because the former are subjected to greater water stress. North-facing areas in
Mediterranean climates have higher humidity and, consequently, pastures have higher vigor and greenness. In addition, because north- and south-facing slopes differ in solar radiation and wind and rain patterns (mainly, from the northwest in winter), the former are cooler and wetter and, therefore, more productive (Golodets and Boeken 2006). Furthermore, the sheep chose north-facing areas because the pastures probably have the highest nutritional quality and the thermal comfort provided by that aspect (GarciaGonzalez et al 1990).

Table 6 Expected and observed frequencies of slope (18-20 monitoring period).

\begin{tabular}{|c|c|c|c|c|c|c|}
\hline Variable & & $\mathrm{N}_{0}$ & $\mathrm{~N}_{\mathrm{E}}$ & $\mathrm{R}$ & $\chi^{2}$ & $P$-value \\
\hline \multirow{4}{*}{ Slope } & $0-2$ & 713 (9.3\%) & 655 (8.6\%) & $+58(+0.7 \%)$ & \multirow{4}{*}{21.662} & \multirow{4}{*}{0.000} \\
\hline & $2-4$ & $2,040(26.8 \%)$ & $2,214(29.0 \%)$ & $-174(-2.2 \%)$ & & \\
\hline & $4-6$ & $2,201(28.8 \%)$ & 2,143 (28.1\%) & $+58(+0.7 \%)$ & & \\
\hline & $>6$ & $2,682(35.1 \%)$ & $2,624(34.3 \%)$ & $+58(+0.7 \%)$ & & \\
\hline
\end{tabular}

*Statistically significant differences $P<0.05$

${ }^{*} N_{\mathrm{O}}$ : Observed frequencies (sheep locations distribution); $\mathrm{N}_{\mathrm{E}}$ : Expected frequencies (terrain distribution); R: Remainder; $\chi^{2}$ : Chi-square value

Table 7 Expected and observed frequencies of aspect and slope within the HS (18-20 monitoring period).

\begin{tabular}{|c|c|c|c|c|c|c|}
\hline Variable & & $\mathrm{N}_{0}$ & $\mathrm{~N}_{\mathrm{E}}$ & $\mathrm{R}$ & $\chi^{2}$ & $P$-value \\
\hline \multirow{4}{*}{ Slope } & $0-2$ & 322 (9.8\%) & 240 (7.3\%) & $+82(+2.5 \%)$ & \multirow{4}{*}{414.913} & \multirow{4}{*}{0.000} \\
\hline & $2-4$ & $1194(36.3 \%)$ & 779 (23.7\%) & $+415(+12.6 \%)$ & & \\
\hline & $4-6$ & 942 (28.7\%) & 979 (29.8\%) & -37 (- 1.1\%) & & \\
\hline & $>6$ & 827 (25.2\%) & 1287 (39.2\%) & $-460(-14.0 \%)$ & & \\
\hline \multirow{4}{*}{ Aspect } & North & 1834 (55.8\%) & 1074 (32.7\%) & $+760(+23.1 \%)$ & \multirow{4}{*}{799.290} & \multirow{4}{*}{0.000} \\
\hline & East & $89(2.7 \%)$ & 144 (4.4\%) & $-55(-1.7 \%)$ & & \\
\hline & South & 304 (9.2\%) & 457 (13.9\%) & $-153(-4.7 \%)$ & & \\
\hline & West & 1058 (32.3\%) & $1610(49.0 \%)$ & $-552(-16.7 \%)$ & & \\
\hline
\end{tabular}

*Statistically significant differences $P<0.05$

${ }^{*} N_{\mathrm{O}}$ : Observed frequencies (sheep locations distribution); $\mathrm{N}_{\mathrm{E}}$ : Expected frequencies (terrain distribution); R: Remainder; $\chi^{2}$ : Chi-square value; HS: Hot Spot

\subsection{Effect of slope}

Sheep can graze on almost any slope, but if the terrain is steep and rugged, the animals spend more time and energy moving to find suitable areas for grazing, which leaves less time for foraging (Vallentine 2001). Therefore, it seems reasonable that, if sheep had no physical limitations and 
could move around freely, they would likely choose flat or nearly flat areas for grazing. In addition, if the herbage is plentiful and freely available, sheep will graze mainly on the lower slopes but, if the herbage is less abundant, sheep will also graze the steeper slopes (López et al 2003). Other biotic or abiotic factors (e.g., soil properties, the content of mineral elements, or the nutritional quality of the pasture), rather than slope per se might influence the apparent preference of sheep for gentle slopes for grazing (Ganskopp and Vavra 1987).

Although the $18-20$ flock did not show a marked preference for the 2-4\% slopes as did the 09-10 flock, nearly $65 \%$ of the records were from slopes $<6 \%$, reflecting the sheep's preference for gentle slopes. Apparently, sheep, where possible, select gentle slopes for grazing rather than steeper areas, where the grasses tend to be less nutritious and less palatable to the animals (Aldezabal et al 1999; García-González et al 2011).

\subsection{Analysis of spatial distribution}

The directional distribution mirrored the relief model, adapting its orientation to the contours. That is, when the sheep move and graze freely, they choose areas where they can move and graze more easily. In short, the analysis of the spatial patterns of the HS indicated that the flock had a clear preference for areas that had slopes between $2 \%$ and $4 \%$ and northern aspects, which was the same for the entire study area.

\section{Conclusions}

The large exodus of humans from rural to urban areas and the intensification of production systems diminished traditional grazing practices and, consequently, led to the loss of traditional knowledge about livestock behavior while grazing. Shepherds know that grazing animals' behavior is not random and depends on terrain and food factors. However, this insight acquired through patient and lengthy contact with the animals is about to get loss.

In this work, conducted in the community pastures in Fariza, Spain, it was shown that the spatial distribution of grazing Churra sheep was non-random because the animals seem to develop common behavioral patterns. Particularly, vegetation height, LU/LC class, and slope and aspect had the most effect on the location of sheep grazing. When grazing, ewes showed strong preferences for areas that had gentle, north-facing slopes, open spaces away from scrublands and trees, and herbaceous layers of grasses. That choice appeared deliberate because it was proven in two independent study periods of two flocks that were evaluated based on different statistical approaches. In short, sheep choose the grazing areas that offer the freshest and most nutritional quality food.

GPS devices for monitoring livestock coupled with remote sensing techniques, particularly LiDAR, have been suggested as very powerful tools to quantify the environmental characteristics and explain the spatial patterns of the livestock freely grazing within it. Beyond the animal's nature, those patterns are influenced by external abiotic (slope and aspect) and biotic (predominant vegetation, plant stratification, height of vegetation, and land use) factors. In this study, terrain characteristics, namely slope, aspect, vegetation height, and LU/LC maps, were retrieved from the LiDAR and imagery datasets. Geotechnologies are not intended to replace traditional pastoralism. Still, they have become an additional resource in decision-making in extensive livestock farming. They support the traditional observations made by farmers and shepherds, therefore paving the way to new management forms of grazing spaces. This fact is beneficial given the decline of traditional practices, which are much more respectful with the rural areas but more difficult to maintain nowadays.

\section{Acknowledgements}

The authors would like to thank Bruce MacWhirter for the English revision of the manuscript.

\section{Conflict of Interest}

The authors declare that there is no conflict of interest.

\section{Funding}

This research did not receive any financial support.

\section{References}

Aldezabal A, Garin I, Garcia-González R (1999) Activity rhythms and the influence of some environmental variables on summer ungulate behaviour in ordesa-monte perdido national park. Pirineos 145:145-156.

Anderson JR, Hardy EE, Roach JT, Witmer RE (1976) A Land Use And Land Cover Classification System For Use With Remote Sensor Data, 1st Editio. Washington.

Arnold GW, Dudzinski ML (1978) Ethology of Free Ranging Domestic Animals. Elsevier Scientific Publishers, Amsterdam.

Baccini A, Goetz SJ, Walker WS, et al (2012) Estimated carbon dioxide emissions from tropical deforestation improved by carbon-density maps. Nat Clim Chang 2:182-185.

Bertolozzi-Caredio D, Garrido A, Soriano B, Bardaji I (2021) Implications of alternative farm management patterns to promote resilience in extensive sheep farming. A Spanish case study. J Rural Stud 86:633-644.

Castro M, Fernández-Núñez E (2016) Seasonal grazing of goats and sheep on Mediterranean mountain rangelands of northeast Portugal. Livest Res Rural Develpment 28:1-13.

Chen Q, Vaglio Laurin G, Battles JJ, Saah D (2012) Integration of airborne lidar and vegetation types derived from aerial photography for mapping aboveground live biomass. Remote Sens Environ 121:108-117.

Clark D, Litherland A, Mata G, Burling-Claridge R (2009) Pasture monitoring from space. In: Proceedings of the South Island Dairy Event. pp 108-123.

Escribano AJ (2019) The Dehesa System for Livestock Production. Evolution, Conservation Issues and Livestock Planning for Sustainability. In: Squires VR, Bryden WL (eds) Livestock: Production, Management Strategies and Challenges. NOVA.

Escribano, Elghannam A, Mesias FJ (2020) Dairy sheep farms in semi-arid rangelands: A carbon footprint dilemma between intensification and landbased grazing. Land use policy 95:104600.

Fernández Carmona J, Blas Ferrer E, Cervera Fras C et al (2017) Datos sobre conducta y bienestar de animales en granja. Universidad Politécnica de Valencia, Valencia. 
Food and Agriculture Organization of the United Nations (FAO) (2004) National forest inventory. Field manual. Template, Forestry D. Rome.

Foody GM (2002) Status of land cover classification accuracy assessment. Remote Sens Environ 80:185-201.

Ganskopp D (2001) Manipulating cattle distribution with salt and water in large arid-land pastures: a GPS/GIS assessment. Appl Anim Behav Sci 73:251262.

Ganskopp D, Vavra M (1987) Slope Use by cattle, feral horses, deer, and bighorn shee. Northwest Sci 61:74-81.

García-González R, Reiné R, Pérez S et al (2011) Comportamiento de ovinos en pastoreo libre y guiado por pastor en un puerto pirenaico. Prod. Anim. 400-407.

Ghosh A, Fassnacht FE, Joshi PK, Kochb B (2014) A framework for mapping tree species combining hyperspectral and LiDAR data: Role of selected classifiers and sensor across three spatial scales. Int J Appl Earth Obs Geoinf 26:49-63.

Glimp HA, Swanson S (1994) Sheep Grazing and Riparian and Watershed Management. Sheep Res. J. 65-71.

Golodets C, Boeken B (2006) Moderate sheep grazing in semiarid shrubland alters small-scale soil surface structure and patch properties. Catena 65:285291.

Handcock RN, Swain DL, Bishop-Hurley GJ et al (2009) Monitoring animal behaviour and environmental interactions using wireless sensor networks, GPS collars and satellite remote sensing. Sensors 9:3586-3603.

Harris NR, Johnson DE, George MR, Mcdougald NK (2002) The Effect of Topography, Vegetation, and Weather on Cattle Distribution at the San Joaquin Experimental Range, California. In: Fifth Symposium on Oak Woodlands: Oaks in California's Challenging Landscape. Albany, CA, pp 5363.

Herrera O (2018) Comportamiento en pastoreo del ganado bovino criollo Argentino y aberdeen angus ecotipo Riojano, en pastizales naturales del chaco árido. Universidad Nacional del Mar de Plata.

Hulbert IAR, French J, Hulbert IANAR, Frencht J (2019) The Accuracy of GPS for Wildlife Telemetry and Habitat Mapping. Br Ecol Soc 38:869-878.

Launchbaugh KL, Howery LD (2005) Understanding landscape use patterns of livestock as a consequence of foraging behavior. Rangel Ecol Manag 58:99-108.

Lillesand T, Kiefer RW, Chipman J (2015) Remote Sensing and Image Interpretation, 7th Editio. Wiley, New York.

Lim K, Treitz P, Wulder $M$ et al (2003) LiDAR remote sensing of forest structure. Prog Phys Geogr Earth Environ 27:88-106.

López IF, Hodgson J, Hedderley DI et al (2003) Selective defoliation by sheep according to slope and plant species in the hill country of New Zealand. Grass Forage Sci 58:339-349.

Mora-Delgado J, Nelson N, Fauchille A, Utsumi S (2016) Application of GPS and GIS to study foraging behavior of dairy cattle. Agron Costarric 40:81-88. Nadal-Romero E, Petrlic K, Verachtert E et al (2014) Effects of slope angle and aspect on plant cover and species richness in a humid Mediterranean badland. Earth Surf Process Landforms 39:1705-1716.

Pandey V, Kiker GA, Campbell KL et al (2009) GPS Monitoring of Cattle Location Near Water Features in South Florida. Appl Eng Agric 25:551-562.
Percival NS, Knowles RL (1983) Combinations of Pinus radiata and pastoral agriculture in New Zealand hill country. In: Hannawey DB (ed) Foothill for Food and Forest. Oregon State University, Corvallis, pp 185-202.

Priya CA, Balasaravanan T, Thanamani AS (2012) An efficient leaf recognition algorithm for plant classification using support vector machine. In: International Conference on Pattern Recognition, Informatics and Medical Engineering, PRIME 2012. pp 428-432.

Putfarken D, Dengler J, Lehmann S, Härdtle W (2008) Site use of grazing cattle and sheep in a large-scale pasture landscape: A GPS/GIS assessment. Appl Anim Behav Sci 111:54-67.

Saini R, Ghosh SK (2018) Crop Classification on Single Date Sentinel-2 Imagery Using Random Forest and Suppor Vector Machine. ISPRS - Int Arch Photogramm Remote Sens Spat Inf Sci XLII-5:683-688.

Schieltz JM, Okanga S, Allan BF, Rubenstein DI (2017) GPS tracking cattle as a monitoring tool for conservation and management. African J Range Forage Sci 34:173-177.

Schoenbaum I, Kigel J, Ungar ED et al (2017) Spatial and temporal activity of cattle grazing in Mediterranean oak woodland. Appl Anim Behav Sci 187:4553.

Senft RL, Coughenour MB, Bailey DW,et al (1987) Large Herbivore Foraging and Ecological Hierarchies. Bioscience 37:789-799.

Shi Y, Wang T, Skidmore AK, Heurich M (2020) Improving LiDAR-based tree species mapping in Central European mixed forests using multi-temporal digital aerial colour-infrared photographs. Int J Appl Earth Obs Geoinf 84:110.

Sillero N, Gonçalves-Seco L (2014) Spatial structure analysis of a reptile community with airborne LiDAR data. Int J Geogr Inf Sci 28:1709-1722.

Silverman BW (1986) Estimación de densidad para las estadísticas y el análisis de datos. New York.

Su Y, Guo Q, Fry DL et al (2016) A Vegetation Mapping Strategy for Conifer Forests by Combining Airborne LiDAR Data and Aerial Imagery. Can J Remote Sens 42:1-15.

Turner LW, Anderson M, Larson BT (2001) Global Positioning Systems (GPS) and Grazing Behavior in Cattle. In: Stowell RR, Bucklin R, Bottcher RW (eds) Livestock Environment VI: Proceedings of the 6th International Symposium ASABE. St. Joseph, pp 640-650.

Turner LW, Udal MC, Larson BT, Shearer SA (2000) Monitoring cattle behavior and pasture use with GPS and GIS. Can J Anim Sci 80:405-413.

Vallentine JF (2001) Grazing management. Academic Press.

Venter ZS, Hawkins HJ, Cramer MD (2019) Cattle don't care: Animal behaviour is similar regardless of grazing management in grasslands. Agric Ecosyst Environ 272:175-187.

Yandún Narváez FJ, Salvo del Pedregal J, Prieto PA et al (2016) LiDAR and thermal images fusion for ground-based 3D characterisation of fruit trees. Biosyst Eng 151:479-494.

Zhang C, Xie Z, Selch D (2013) Fusing lidar and digital aerial photography for object-based forest mapping in the Florida Everglades. GIScience Remote Sens 50:562-573. 